\title{
O PROCESSO DE MERCANTILIZAÇÃO DA AGRICULTURA FAMILIAR NO ALTO URUGUAI-RS
}

\section{THE COMMERCIALIZATION PROCESS OF THE FAMILY FARMING IN ALTO URUGUAY REGION-RS}

\section{EL PROCESO DE MERCANTILIZACIÓN DE LA AGRICULTURA FAMILIAR EN ALTO URUGUAY-RS}

\author{
Zenicléia Angelita Deggerone ${ }^{1}$ \\ https://orcid.org/0000-0003-4286-4686 \\ Sergio Schneider ${ }^{2}$ \\ https://orcid.org/0000-0002-4353-6732
}

Submissão: 30/07/2021 / Aceito: 28/09/2021 / Publicado: 04/02/2022.

\begin{abstract}
Resumo
Este artigo tem por objetivo apresentar alguns elementos sócio-históricos que exerceram influência no processo de mercantilização dos agricultores familiares na região Alto Uruguai-RS. O estudo desenvolveu uma abordagem qualiquantitativa, tendo sido realizada uma análise descritiva de dados primários, coletados a partir de entrevistas com atores chaves entre janeiro e abril de 2020 e de informações secundárias, obtidas por meio de pesquisas bibliográficas e documentais. Os resultados deste artigo evidenciam que o Estado, por meio da implementação de mecanismos institucionais (leis, portarias, decretos), políticas públicas de comercialização e de crédito, ofereceu condições para que ocorressem a modernização das atividades produtivas e o crescimento da produção agroalimentar, o que resultou na ampliação do processo de mercantilização. Entre as implicações que esse processo social gerou, os agricultores transformaram-se em produtores simples de mercadorias, mas isso não alterou a condição dessa categoria social, uma vez que as normas, as regras e os valores sociais que regem as relações entre os atores sociais no interior dos grupos familiares não desapareceram em razão da intensificação das trocas.
\end{abstract}

Palavras-chave: agricultores familiares, Estado, mercantilização, políticas públicas, produtores simples de mercadorias.

\begin{abstract}
This article aims to present some socio-historical elements that influenced the commercialization process of family farmers in the Alto Uruguai Region-RS. The study developed a qualiquantitative approach, having been carried out a descriptive analysis of primary data, collected from interviews with key actors between January and April 2020, and secondary information, obtained through bibliographic and documentary research. The results of this article show that the State, through the institutional mechanisms implementation (laws, ordinances, decrees), public commercialization and credit policies, offered conditions to productive activities modernization and the growth of

\footnotetext{
${ }^{1}$ Doutora em Desenvolvimento Rural (UFRGS); Professora Adjunta na Universidade Estadual do Rio Grande do Sul (UERGS) - Unidade Universitária em Erechim (RS). E-mail: zenicleiadeggerone@ gmail.com

${ }^{2}$ Professor Titular dos Programas de Pós Graduação em Sociologia (PPGS) e Desenvolvimento Rural (PGDR) na Universidade Federal do Rio Grande do Sul (UFRGS) - Porto Alegre (RS); Bolsista Produtividade em Pesquisa CNPq, PQ1B. E-mail: schneide@ufrgs.br
} 
agrifood production to take place, which resulted in the expansion of the mercantilization process. Among the implications that this social process generated, farmers were transformed into simple producers of goods, but this did not change the condition of this social category, since the norms, rules and social values that govern the relationships between social actors within the family groups they did not disappear due to the intensification of exchanges.

Keywords: family farmers, State, mercantilization, public policies, simple goods producers.

Resumen
Este artículo tiene por objetivo presentar algunos elementos socio-históricos que ejercieron influencia en el proceso de mercantilización de los agricultores familiares en la región Alto Uruguay-RS. El estudio desarrolló un enfoque cuali-cuantitativo, con la realización de um análisis descriptivo de datos primarios, recogido a partir de entrevistas con sctores claves entre enero y abril de 2020, y de informaciones secundarias, obtenidas por medio de investigaciones bibliográficas y documentales. Los resultados de este artículo evidencian que el Estado, por medio de implementación de mecanismos institucionales (leyes, ordenanzas, decretos), políticas públicas de comercialización y de crédito, ofreció condiciones de modo que ocurrieran la modernización de las actividades productivas y el crecimiento de la producción agroalimentar, lo cual resultó en la ampliación del proceso de mercantilización. entre las implicaciones que este proceso social generó, los agricultores se transformaron em productores simples de mercancías, pero esto no modificó la condición de esta categoria social, ya que las normas, las reglas y los valores sociales que rigen las relaciones entre los actores sociales dentro de los grupos familiares no desaparecieron en razón de la intensificación de los intercambios.

Palabras-clave: agricultores familiares, Estado, mercantilización, políticas públicas, productores simples de mercancías.

\section{INTRODUÇÃO}

O debate sobre a mercantilização da agricultura familiar ${ }^{\mathrm{i}}$ no Brasil teve início com os estudos de Abramovay (1992, 1998), ao reconhecer que a passagem do campesinato para a agricultura familiar estava atrelada ao processo de integração aos mercados. Além desse autor, Maria de Nazareth Baudel Wanderley concorda com essa mesma perspectiva e considera que os agricultores familiares formam uma categoria social capaz de adaptar-se, transformar-se e diferenciar-se, por conta de sua capacidade de integração com os espaços de comercialização (WANDERLEY, 2009).

Nesse cenário, a discussão sobre a mercantilização tem ganhado notoriedade com a produção de estudos que abordam as estratégias de inserção social e econômica dos agricultores familiares. Tal contexto levou à evidência de pesquisas que abordam: a construção social dos mercados, especialmente a importância das feiras para a comercialização de alimentos (CASSOL, 2013; 2018; OLIVEIRA, 2014; SILVA, 2016); os circuitos curtos de comercialização de produtos das agroindústrias familiares (FERRARRI, 2011; SCARBELOT, 2012; GAZOLLA, 2017); o 
papel das cadeias curtas e das redes agroalimentares alternativas (GAZOLLA; SCHNEIDER, 2017); os mercados institucionais (GRISA, 2009, 2010, 2012; TRICHES, 2012, 2015); e os nested markets (PLOEG; JINGZHONG; SCHNEIDER, 2012; SCHNEIDER; SALVATE BRASIL; CASSOL, 2016; SALVATE BRASIL, 2019).

Esses estudos evidenciam que a mercantilização, enquanto um amplo processo social, tem levado os atores sociais a acessarem um conjunto heterogêneo de espaços de comercialização. Isso se justifica em razão de que, segundo Ploeg (1992), a mercantilização é a passagem da forma de valor de uso de um bem material para a forma de valor de troca, o que faz com que o processo de organização do trabalho passe a ser orientado para os intercâmbios com o mercado, com grande intensificação das relações mercantis. Ainda de acordo com o autor, essa integração tem criado um processo multifacetado que assume distintos contornos no contexto em que operam as formas familiares de produção (PLOEG, 2006).

Entre os pesquisadores que têm se dedicado a analisar esse tema, Maluf (1995; 2004), Wilkinson (2008), Abramovay et al. (2003) e Schneider (2016) constataram essa diversidade de espaços de comercialização que os agricultores familiares passaram a acessar nos últimos anos. A integração das formas familiares de produção pode se dar por meio das cadeias longas e dos circuitos regionais e locais de comercialização (MALUF; 1995; 2004); bem como com as cooperativas, agroindústrias e mercados locais (ABRAMOVAY et al., 2003) e com os mercados de commodities, especialidades, orgânicos, artesanais, solidários e institucionais (WILKINSON, 2008). De acordo com Schneider (2016), os atores sociais têm participado em mercados de proximidade, territoriais, convencionais e institucionais.

Haja vista a pluralidade de formas de integração e o papel conferido às trocas econômicas na reprodução socioeconômica da agricultura familiar, essa categoria social na região Alto Uruguai (RS) presenciou profundas transformações ao longo dos últimos anos. Essas alterações geraram um ambiente social distinto e heterogêneo entre os agricultores e têm transformado paulatinamente esses atores sociais em produtores simples de mercadorias ${ }^{\mathrm{ii}}$. Além disso, essas transformações provocaram mudanças nas práticas agrícolas, nas formas de organização do trabalho, nos padrões de consumo, nos princípios de sociabilidade e nas representações sociais.

Essas variações são decorrentes de um conjunto de mecanismos institucionais que são inseparáveis do contexto histórico, social, político e cultural dos agricultores familiares. Por isso, na tentativa de identificar alguns desses aspectos que tiveram influência na integração econômica da agricultura familiar nessa região, o presente artigo tem como objetivo apresentar alguns 
elementos sócio-históricos que exerceram influência na mercantilização dessa categoria social na região Alto Uruguai-RS.

O Alto Uruguai-RS é uma região posicionada ao norte do estado do Rio Grande do Sul, formado por $32^{\mathrm{iii}}$ municípios. A Figura 1 apresenta a localização geográfica da região analisada.

Figura 1 - Localização geográfica da região Alto Uruguai-RS

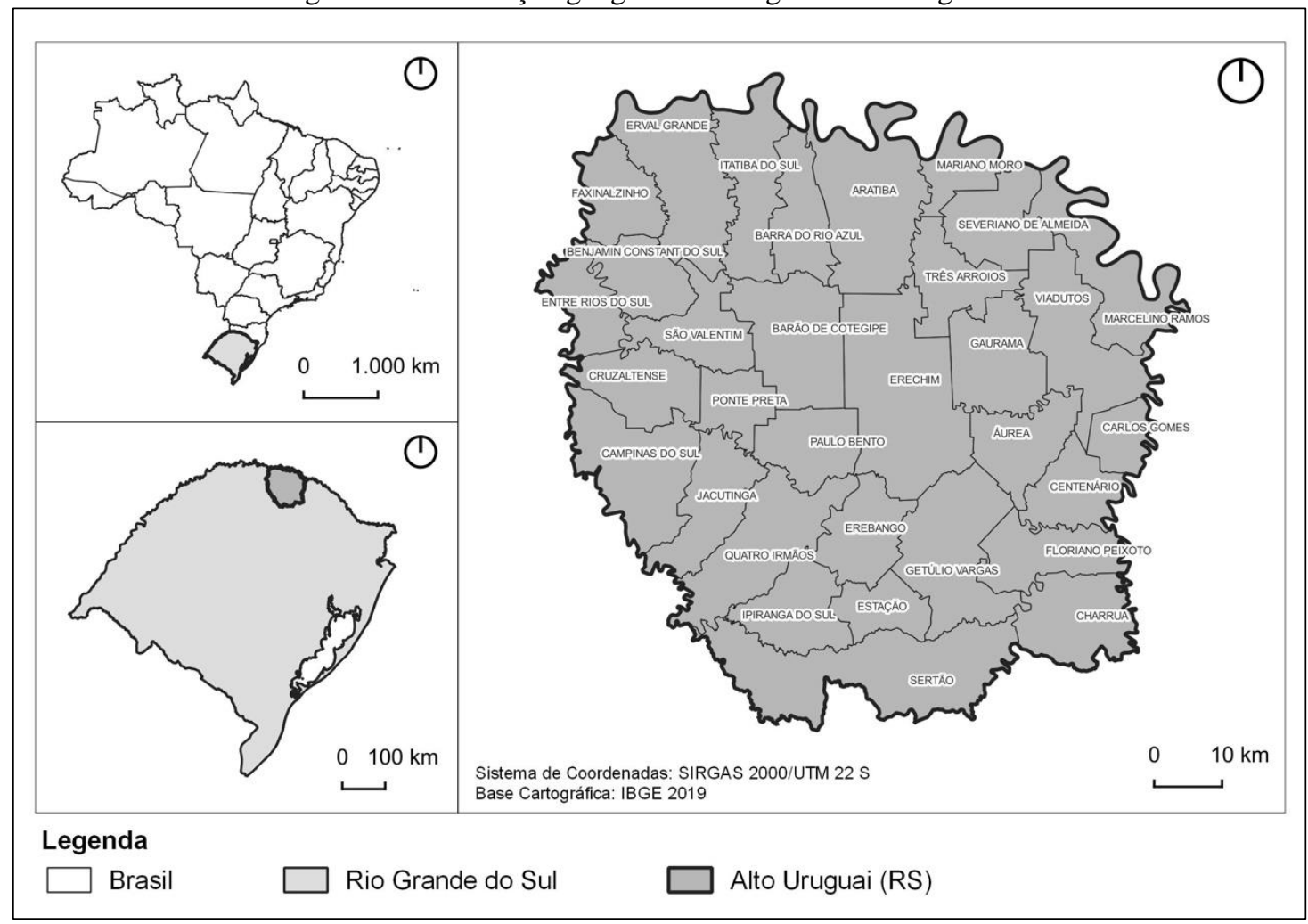

Fonte: Dados da Pesquisa (2021).

O presente estudo utilizou uma abordagem qualiquantitativa, tendo sido realizada uma análise descritiva de dados primários e secundários. As informações de natureza primária foram obtidas por meio de entrevistas não estruturadas com agricultores familiares, coordenadores de cooperativas e organizações sindicais, entre os meses de janeiro e abril de 2020. Os dados secundários foram coletados por meio de pesquisas bibliográficas e documentais. Essas informações foram levantadas em livros, jornais, revistas, dissertações, teses, artigos e documentos estatísticos disponíveis em bancos de dados públicos, tais como: Pesquisa Agrícola Municipal (PAM), Instituto Brasileiro de Geografia e Estatística (IBGE) e valores financiados pelo crédito agrícola e pecuário no Banco Central (BC).

Após o levantamento das informações, as entrevistas foram sistematizadas e categorizadas por meio da técnica de análise de conteúdo (BARDIN, 2011). Os procedimentos adotados para 
analisar os dados envolveram: pré-análise, exploração do material e tratamento dos resultados obtidos a partir da pesquisa de campo. Os dados secundários quantificaram a produção agrícola e pecuária e foram categorizados e analisados por tipo de produto agropecuário, município pertencente à região Alto Uruguai e ano (1974 a 2018). Em relação aos valores financiados pelo crédito agrícola e pecuário, os dados foram classificados por tipo de financiamento (custeio/investimento), produto agrícola ou atividade produtiva, município e ano (2013 a 2018).

Para além dessa introdução, o artigo está dividido em quatro seções. A primeira aborda os precedentes históricos da conformação mercantil na região Alto Uruguai-RS. Em seguida, analisase o processo de mercantilização dos agricultores familiares a partir dos anos 2000, o que possibilita a identificação dos elementos que aceleraram o processo de integração mercantil dos agricultores familiares dessa região. Na terceira seção, apresenta-se as implicações do processo de mercantilização para a agricultura familiar. E, por fim, na última seção, são tecidas algumas considerações e é apresentado o referencial utilizado neste artigo.

\section{PRECEDENTES HISTÓRICOS DA CONFORMAÇÃO MERCANTIL NA REGIÃO ALTO URUGUAI-RS}

A povoação dessa região, pelo projeto de colonização oficial do estado, tem seus registros históricos a partir de 1900. No entanto, antes disso, esse território já se encontrava ocupado por diferentes grupos de indígenas e caboclos que se dedicavam à coleta de erva-mate e alimentos para o autoconsumo. A implantação de núcleos colonizadores nessa região propiciou a vinda de migrantes e imigrantes, principalmente italianos, alemães e poloneses, a partir de 1908. Esse período assinalou o início de um novo marco nas relações de troca, pois os sistemas produtivos implementados na região, baseados na agricultura e na criação de pequenos animais, foram organizados a partir do trabalho familiar (PIRAN, 2001; CHIAPARINI et al., 2012).

O desenvolvimento da agricultura familiar na região Alto Uruguai passou por diferentes fases, o que gerou distintos modos e formas de inserção aos mercados. A partir do trabalho pioneiro de Piran $(2001)^{\text {iv }}$, que identificou quatro períodos, este estudo destaca que os agricultores familiares estariam passando por cinco fases, haja vista a intensificação do processo de mercantilização das atividades produtivas a partir dos anos 2000.

A primeira fase de interação com os mercados (1900 - 1939) pode ser denominada de sistema produtivo colonial. As famílias extraíam madeira e erva-mate como forma de gerar excedentes para pagar a compra do lote colonial. Também nessa fase, os agricultores familiares 
passaram a produzir alimentos para serem vendidos ou trocados por produtos manufaturados. Esse sistema funcionava a partir da troca - realizada com os comerciantes - dos produtos agrícolas produzidos pela pequena propriedade policultora (milho, trigo, feijão, mandioca e outros produtos) por materiais ou utensílios que eram utilizados nas propriedades rurais (louças, calçados, chapéus, açúcar, sal, querosene, tecidos ferramentas, etc.)(PIRAN, 2001; CHIAPARINI et al., 2012).

Nesse período, a atividade suinícola ${ }^{\mathrm{v}}$, além de possibilitar a geração de alimentos para as famílias, se tornou uma das principais fontes de renda. Os agricultores vendiam a banha bruta ou os animais para os comerciantes e frigoríficos que realizavam o processamento dos produtos agroalimentares.

Piran (2001) enfatiza que a manutenção das propriedades rurais, nessa fase, decorreu da autonomia produtiva policultora destinada ao autoconsumo e à eventual venda da produção excedente. Ainda segundo o autor, a comercialização desses produtos era realizada nas casas de comércio localizadas nas comunidades rurais e em vilarejos, e também com as cooperativas coloniais e indústrias artesanais, vinculadas à produção agropecuária, sendo, primordialmente, os moinhos, as atafonas, os frigoríficos e a indústria da erva-mate.

A segunda fase de desenvolvimento da agricultura compreendeu uma maior integração aos mercados e abrangeu o período de 1940 a 1969. Nesse período, o Alto Uruguai passou por um processo significativo de mudanças na base técnico-produtivista da agricultura, que podem ser caracterizadas pela diversificação de atividades produtivas destinadas à geração de excedentes e pelo aprofundamento das relações mercantis dos agricultores com os espaços de comercialização.

Nesse período, o Estado brasileiro incentivou a produção de trigo e isso culminou na criação de duas grandes cooperativas tritícolas, quais sejam a Cooperativa Tritícola de Erechim Ltda (COTREL) e a Cooperativa Tritícola de Getúlio Vargas Ltda (COTRIGO). Ambas as organizações foram fundadas em 1957 e tinham por objetivo incentivar a produção do cereal e conceder a assistência necessária aos agricultores, auxiliando, assim, os produtores na produção, no armazenamento e na comercialização do produto (PIRAN, 2001).

Nesse período, os agricultores familiares buscaram se especializar em alguns cultivos destinado para a venda e outros para o autoprovisionamento familiar. As famílias passaram a cultivar o trigo para vender e o milho para alimentar os suínos também destinados à venda; e produziam o feijão, leite, frutas e outros produtos para o consumo doméstico. Com essa alteração no sistema produtivo colonial, a produção agropecuária teve um crescimento exponencial, o que 
contribui para iniciar o processo de diferenciação social e econômica dos agricultores familiares (SCHNEIDER, 2003).

Embora a produção de suínos e grãos não tenha gerado profundas transformações na base tecnológica das unidades de produção familiares, foi a partir dessas atividades que se iniciaram dois processos sociais de grande importância para a compreensão do processo de transição do sistema produtivo colonial para a intensificação da agricultura de base familiar. De um lado, essas atividades implicaram uma maior especialização dos processos produtivos e, consequentemente, um aumento nos volumes de produção e de uso da força de trabalho familiar. E, por outro lado, impulsionaram uma maior integração ao comércio e às organizações (mercantilização), ocasionando uma monetarização, cada vez mais intensa, da vida social e econômica no meio rural.

O terceiro período de desenvolvimento agropecuário abrangeu os anos de 1970, estendendo-se até o final dos anos de 1980, e se caracterizou pela continuidade do processo de mercantilização, impulsionado por uma transformação estrutural na base produtiva. A "Revolução Verde" ${ }^{\text {,i }}$ disponibilizou um conjunto de máquinas e equipamentos que lentamente foram substituindo a força motriz animal nas propriedades rurais. Ainda assim, propiciou insumos de origem industrial, como fertilizantes e agrotóxicos, bem como de sementes geneticamente melhoradas (PLEIN, 2003) para serem implementadas nas propriedades rurais.

Em decorrência dessa alteração no padrão produtivo e tecnológico, observou-se a redução da produção destinada ao autoconsumo e o aumento dos cultivos voltados à comercialização. Por consequência, presenciou-se o aumento das áreas agrícolas destinadas à produção de soja, milho e trigo e à criação de suínos e aves, que passou a ser realizada de modo integrado ${ }^{\text {vii }}$ e organizada pelas cooperativas e indústrias agroalimentares.

Essa transformação na base produtiva trouxe várias consequências para o meio rural, dentre as quais Piran (2001) evidencia a exclusão dos agricultores familiares de algumas atividades produtivas, por não terem condições de se adequar ao sistema produtivo, e isso levou muitos produtores a mudar de ramo de produção ou a migrar para os centros urbanos. Além dessas implicações sociais, as cooperativas agropecuárias reestruturaram e alteraram a dinâmica dos mercados locais, pois intensificaram a circulação de mercadorias, ao mesmo tempo em que contribuíram para a criação de certas condições fundamentais para a reprodução destes como produtores simples de mercadorias, na produção de aves e suínos nessa região.

Entre o início dos anos 1990 e o início dos anos 2000, a agricultura familiar no Alto Uruguai continuou implementando o modelo agroalimentar que estava em curso, pautado na 
intensificação da produção de grãos e na seleção dos produtores integrados ao complexo de carnes. Além disso, os efeitos da conjuntura macroeconômica nacional dos anos $1990^{\text {viii }}$, juntamente com problemas locais, acabaram desencadeando várias adversidades, a destacar: a migração dos jovens para as cidades, devido à falta de perspectivas de renda nas propriedades rurais; o fracionamento contínuo da partilha da terra entre os herdeiros (o que inviabilizava a manutenção de muitas famílias no mesmo lote rural); a falta de apoio institucional para os agricultores que possuíam pequenas áreas agrícolas e a modernização seletiva (o que gerou a exclusão de muitos agricultores das cadeias de produção); e vários problemas climáticos (sucessivas estiagens). Além disso,a falta de políticas públicas compensatórias descapitalizava os agricultores familiares.

Por conta desse panorama, Seminotti (2014) e Zanella (2004) ressaltam que várias organizações sociais ligadas aos trabalhadores do campo e da cidade atuaram na organização de novas cooperativas, associações e agroindústrias para comercializarem e remunerarem adequadamente os produtos da agricultura familiar. Além disso, as organizações dos agricultores familiares também contribuem para a criação e a implementação do Programa Nacional de Fortalecimento da Agricultura Familiar (PRONAF) e para o seguro agrícola nesse período (ZANELLA, 2004). Esse autor também salienta que a organização e a mobilização dos agricultores familiares contribuíram para a criação de mecanismos ou "contramovimentos" para acessar novos mercados para os produtos da agricultura familiar até então excluídos dos tradicionais canais de comercialização (cooperativas empresariais, agroindústrias, indústrias...) (ZANELLA, 2004).

Além disso, a criação do PRONAF, em 1995, e sua institucionalização, em 1996, significaram um marco para a diversificação produtiva com inserção dos agricultores familiares em circuitos curtos de comercialização. Além disso, essa política pública contribuiu na reconversão de atividades produtivas e, em alguns casos, também acelerou o processo de especialização via mercado de commodities, como será discutido na quinta fase de desenvolvimento da agricultura familiar.

A conformação mercantil dos produtores dessa região, a partir dos anos 2000, passou a incorporar novos mecanismos que irão incidir na ampliação dos processos de diferenciação social e produtiva dos agricultores familiares. Por isso, no que refere ao tempo posterior a esse período, a próxima seção deste artigo busca apresentar alguns fatos sócio-históricos que passaram a intensificar a participação dos agricultores familiares nos mercados agroalimentares. 
Revista Grifos - Unochapecó

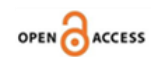

DOI: http://dx.doi.org/10.22295/grifos.v31i56.6596 | Edição Vol. 31, Núm. 56, 2022. 


\section{INTEGRAÇÃO ECONÔMICA, ESPECIALIZAÇÃO PRODUTIVA E DISTINTIVIDADE MERCANTIL ENTRE 2000 e 2018}

Os anos 2000 marcam a continuidade do processo de mercantilização e da especialização produtiva dos agricultores familiares, estendendo-se até os dias atuais. Porém, a partir desse período, o Estado implementou novos mecanismos institucionais formais que passaram a atuar novamente na modernização de alguns produtos agroalimentares. As commodities (grãos, leite, carnes) passaram a estar sujeitas a um conjunto de regulamentações e legislações ${ }^{\text {ix }}$ nacionais e internacionais que, em grande medida, passaram a influenciar decisivamente no processo de concentração e especialização da produção de grãos, aves, suínos, leite e outras cadeias produtivas.

Além dessas transformações, Niederle e Wesz Junior (2018) enfatizam que, nesse período, acontece uma reconfiguração da ordem industrial através de uma nova onda de inovações tecnológicas integradas no campo agrícola (sementes transgênicas, agricultura de precisão, agricultura 4.0); mudanças nas dietas e hábitos de consumo da população ligadas ao crescimento da classe média dentro e fora do país (alimentos ultraprocessados); expansão da fronteira agropecuária para novas áreas, impulsionada pela expansão das commodities; e fusões, aquisições e joint ventures de empresas, levando à concentração e à transnacionalização do sistema agroalimentar.

Essas mudanças institucionais provocaram alterações nos principais ramos de produção desenvolvidos na região Alto Uruguai. A produção de aves e suínos e o cultivo de grãos passaram a formar um conjunto de atividades produtivas altamente mercantilizadas e seletivas na divisão do trabalho. A produção de leite segue na mesma esteira da integração mercantil, porém, adentrou mais tardiamente que os outros ramos de produção. Seguindo o princípio da troca mercantil, mas de modo mais autônomo, a produção de frutas, a horticultura e a agroindustrialização de alimentos preservam características que permitem aos agricultores diversificarem sua produção agroalimentar e fazerem uso de diferentes espaços de comercialização para ofertar sua produção.

Essa constatação da existência de heterogêneas estruturas de produção nessa região atende ao que Ploeg (2006) pontuou sobre a "forma camponesa" e a "forma empresarial" de fazer agricultura. E caminhando sobre esses paralelos, os agricultores familiares, ainda que sejam produtores de mercadorias, buscaram meios para consolidar seu espaço no âmbito de uma sociedade capitalista, e isso lhes possibilitou alcançar seus propósitos (POLANYI, 2012a) e permanecer no meio rural. 
Essa diversidade e coexistência de sistemas de produção é decorrente de um conjunto de políticas públicas direcionadas à construção de novos mercados e que também ocasionaram a intensificação da mercantilização no meio rural. Grisa e Schneider (2014) ponderam que os anos 2000 iniciaram sob o efeito de uma mudança política muito importante, que decorre das eleições presidenciais em 2002, quando Luiz Inácio Lula da Silva assume a Presidência da República.

Essa alteração no cenário político contribuiu para a criação de novos mercados na região, o que se deu a partir da atuação do Estado, que disponibilizou aos agricultores familiares mais recursos financeiros por meio do crédito agrícola e pecuário, destinado à realização de investimentos em diferentes modalidades de financiamento ${ }^{\mathrm{x}}$. Essas linhas de crédito, segundo Gazolla e Schneider (2013), estimularam a produção de diversos alimentos básicos (arroz, feijão, leite, frutas, etc.), por processos de diversificação de atividades rurais (pequenos cultivos e criações) e a partir do apoio a pequenas iniciativas agropecuárias, como, por exemplo, a implantação de hortas, pomares e agroindústrias. Porém, outros autores (GRISA; WESZ JUNIOR, 2010; MATTEI, 2011; GAZOLLA; SCHNEIDER, 2013; GRISA; JÚNIOR; BUCHWEITZ, 2014; WESZ JUNIOR, 2020) enfatizam que os recursos do Pronaf Custeio e Investimento foram aplicados principalmente em lavouras temporárias de grãos e commodities, e para a aquisição de máquinas, equipamentos e veículos agrícolas para fornecer infraestrutura rural ao desenvolvimento dessas culturas agrícolas (GAZOLLA; SCHNEIDER, 2013).

Essa constatação pode ser conferida nas Figuras 2 e 3, nas quais são apresentados os valores utilizados pelo Pronaf Custeio e Pronaf Investimento entre 2013 e 2018, na Região Alto Uruguai. No Pronaf Custeio (Figura 2), foram utilizados mais de R\$ 1.324.065.017,35 nesse período para custear os insumos necessários para a produção agrícola. Entre os valores apurados, evidenciou-se que foram financiados cerca de $\mathrm{R} \$ 715.481 .952,77$ para a produção de soja, tendo essa cultura agrícola sido a que mais utilizou recursos financeiros no período. Na produção de milho, foram utilizados $\mathrm{R} \$ 409.253 .916,79$, e a produção de trigo, por sua vez, empregou $\mathrm{R} \$$ 199.329.147,79 para custear as despesas produtivas.

A Figura 2 também expõe outra constatação desse período no que se refere aos investimentos realizados em insumos produtivos, o que contribuiu decisivamente para o aumento de produtividade agrícola (Figura 4). A cultura da soja, em 2017, alcançou o maior valor financiado ( $\mathrm{R}$ \$ 148.560.136,58); a produção de milho teve o maior montante subsidiado em 2016 ( $\mathrm{R} \$$ 88.517.337,22); e a cultura do trigo manteve uma média de $\mathrm{R} \$ 33.221 .524,63$ aplicados na produção do cereal. 
Figura 2 - Utilização do Pronaf Custeio entre 2013 e 2018 na Região Alto Uruguai (RS)

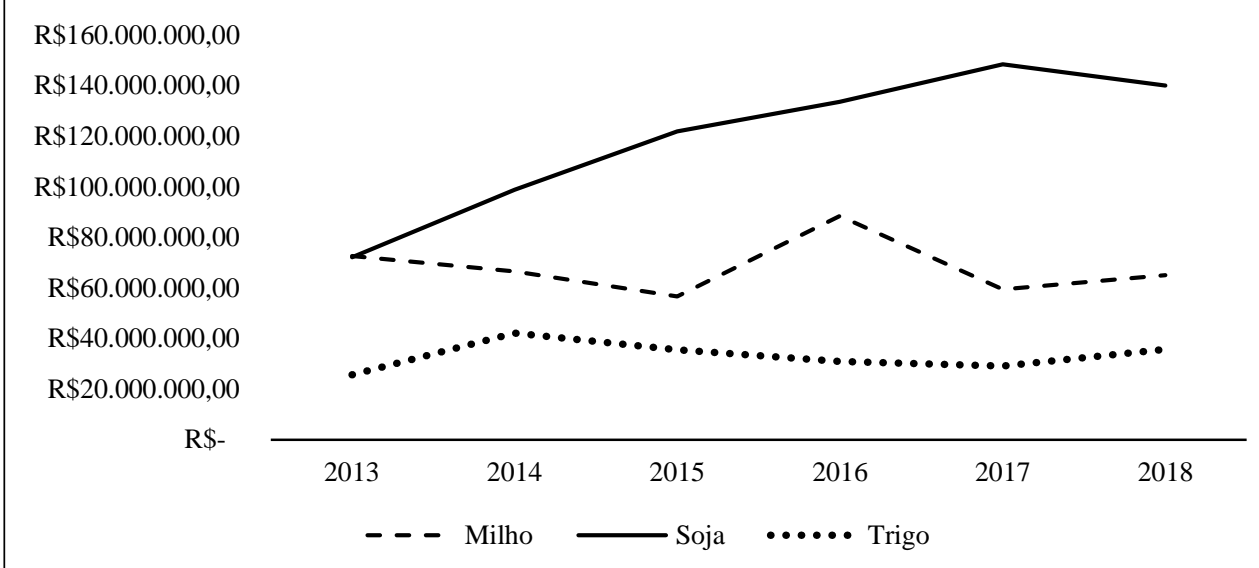

Fonte: Elaborado pelos autores com base em BACEN (2020a).

Em relação ao Pronaf Investimento (Figura 3), foram empregados R \$ 169.378.190,95 nesse período para investir em infraestruturas para a produção de aves, suínos, bovinos de leite, aquisição de máquinas, equipamentos e veículos agrícolas destinados a auxiliar nas atividades agrícolas e pecuárias.

Dentre os valores identificados, a atividade leiteira foi a que mais empregou os recursos do Pronaf Investimento, atingindo mais de R \$ 67.715.491,01. A produção de suínos usou mais de R \$ R \$ 46.854.038,49; a aquisição de máquinas, implementos e veículos agrícolas consumiu R\$ 40.531.861,00; e a produção de aves de corte utilizou pouco mais de R \$ 14.276.800,45.

Figura 3 - Utilização do Pronaf Investimento entre 2013 e 2018 na Região Alto Uruguai (RS)

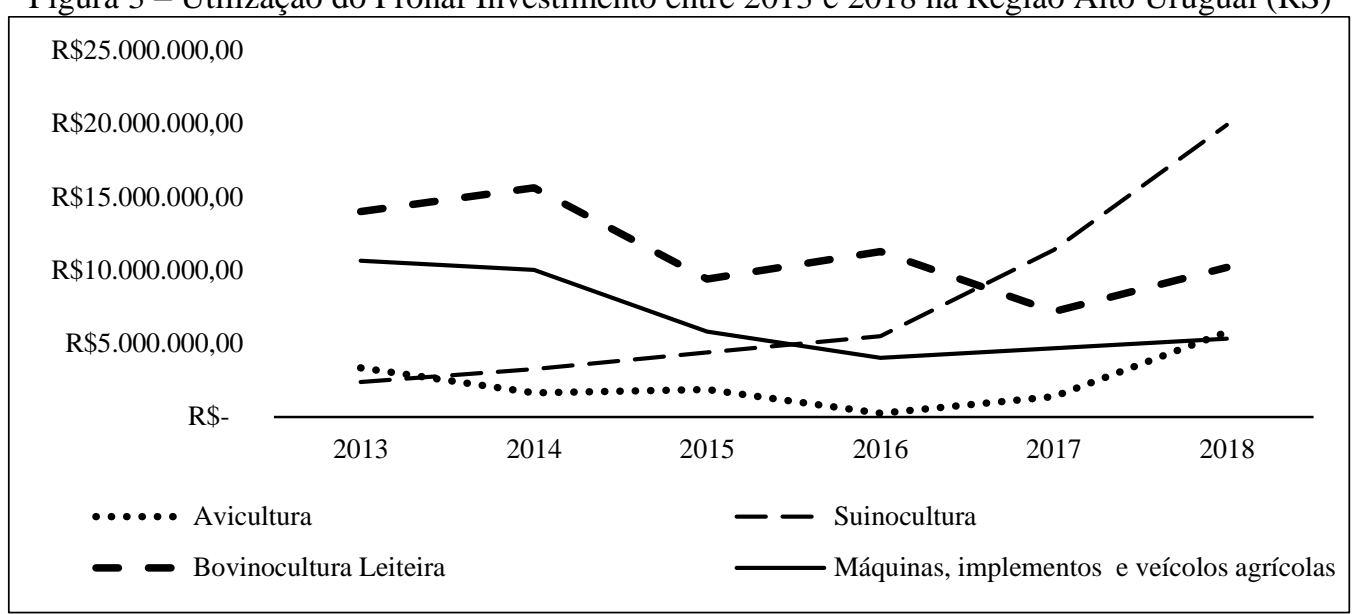

Fonte: Elaborado pelos autores com base em BACEN (2020b). 
A Figura 3 também apresenta algumas informações importantes que incidiram na ampliação e concentração da produção agroalimentar (Figura 5). A atividade leiteira manteve-se com uma média de investimentos de $\mathrm{R} \$ 11.285 .915,17$; a produção de suínos teve os maiores valores financiados em 2018, atingindo R\$ 19.923.916,42; a avicultura registrou, em 2018, o maior valor operacionalizado $(\mathrm{R} \$ 5.791 .511,96)$; e as aquisições de máquinas, implementos e veículos agrícolas empregaram uma média de $\mathrm{R}$ \$ 6.755.310,17 no período analisado.

Dessa forma, por conta da expressividade dos valores financiados pelo Pronaf custeio e do investimento na região, esse período é dividido em duas subseções. A primeira subseção traz alguns elementos que evidenciam como foram construídos os novos mercados para a agricultura familiar. A segunda, por sua vez, procura demostrar como as políticas públicas ao longo desse período intensificaram a especialização e a seletividade mercantil dos agricultores familiares.

\section{A centralidade do Estado na redistribuição e na organização de mercados para a agricultura familiar}

A região Alto Uruguai (RS) é reconhecida pelo engajamento político dos atores sociais (PIRAN, 2001; ZANELLA, 2004), o que tem vínculo com a atuação das organizações sindicais e com a criação de estruturas associativas e cooperativas. A finalidade desses novos espaços era justamente garantir que os agricultores familiares tivessem acesso a novos canais de comercialização e não ficassem limitados às tradicionais cooperativas empresariais, comerciantes e agroindústrias.

Por conta dessa capacidade de articulação liderada pela Confederação Nacional dos Trabalhadores na Agricultura (CONTAG), o Movimento Sem Terra (MST) e a Confederação Nacional dos Trabalhadores na Agricultura Familiar (CONTRAF) pautaram uma atuação mais presente por parte do Estado no desenvolvimento das regiões e dos municípios eminentemente agrícolas. Essas organizações sindicais e sociais tiveram participação decisiva na criação de espaços de trocas para os agricultores familiares.

Dessa forma, o governo brasileiro criou mecanismos institucionais que permitiram a criação de mercados para os produtos oriundos da agricultura familiar. Dentre esses espaços institucionais, o Programa de Aquisição de Alimentos (PAA) ${ }^{\text {xi }}$ instituído em 2003 buscou articular a compra de produtos da agricultura familiar com ações de segurança alimentar (distribuição de alimentos) para a população em vulnerabilidade social. 
Segundo Grisa et al. (2011), o PAA constituiu uma política de fortalecimento da agricultura familiar, sobretudo porque foi um dos canais de comercialização que garantiu a aquisição de produtos pelo Estado por meio de mecanismos diferenciados. $\mathrm{Na}$ região Alto Uruguai, dentre as modalidades ${ }^{\mathrm{xii}}$ existentes do PAA, desde a sua institucionalização, foram adquiridos $\mathrm{R} \$ 4.354 .859,01$ em compras da agricultura familiar, conforme dados emitidos pela Secretaria da Agricultura, Pecuária e Desenvolvimento Rural do Estado do Rio Grande do Sul $(\text { SAPDR/RS, 2020) })^{\text {xiii }}$.

A criação do segundo canal de comercialização, por parte do Estado, se deu em decorrência de uma alteração no Programa Nacional de Alimentação Escolar (PNAE). A partir da Lei nº. 11.947/2009, houve a determinação de que no mínimo 30\% dos recursos federais destinados à compra da alimentação escolar fossem reservados para a aquisição de alimentos dos agricultores familiares (GRISA; SCHNEIDER, 2014).

Triches (2015) destaca que o PNAE se tornou um dos canais institucionais usados para o escoamento da produção agroalimentar dos agricultores familiares e ressalta que isso trouxe contribuições no fortalecimento dessa categoria social. Além disso, o programa possibilitou a criação de novos mercados para os agricultores familiares (REAL; SCHNEIDER, 2011), melhorando as condições socioeconômicas da agricultura familiar.

O PAA e PNAE são o que Schneider (2016) denominou de mercados do tipo institucional. Nesse tipo de mercado, o poder público - seja em nível municipal, estadual ou federal - é o principal comprador que visa atender à demanda alimentar proveniente de escolas, hospitais, universidades, agências penitenciárias e outras instituições públicas.

Na região Alto Uruguai, no período de 2011 a 2017 (Tabela 1), o PNAE adquiriu, em termos financeiros, $\mathrm{R} \$ 14.090 .029,87$, o que perfaz um percentual de $55 \%$ de compras efetuadas de agricultores familiares.

Tabela 1 - Compra da alimentação escolar no Alto Uruguai entre 2011 a 2017 (rede estadual e municipal de ensino)

\begin{tabular}{llllcc}
\hline Ano & Repasses do FNDE & \multicolumn{2}{c}{$\begin{array}{c}\text { Aquisições da Agricultura } \\
\text { familiar (R\$) }\end{array}$} & $\begin{array}{c}\text { Aquisições da Agricultura } \\
\text { familiar (\%) }\end{array}$ \\
\hline 2011 & $\mathrm{R} \$$ & $2.954 .982,00$ & $\mathrm{R} \$$ & $1.266 .864,37$ & $42 \%$ \\
2012 & $\mathrm{R} \$$ & $3.283 .135,60$ & $\mathrm{R} \$$ & $1.792 .551,73$ & $54 \%$ \\
2013 & $\mathrm{R} \$$ & $3.934 .597,00$ & $\mathrm{R} \$$ & $1.907 .662,48$ & $48 \%$ \\
2014 & $\mathrm{R} \$$ & $3.585 .382,00$ & $\mathrm{R} \$$ & $1.833 .428,34$ & $51 \%$ \\
2015 & $\mathrm{R} \$$ & $3.653 .148,00$ & $\mathrm{R} \$$ & $2.217 .353,25$ & $60 \%$ \\
2016 & $\mathrm{R} \$$ & $3.775 .195,20$ & $\mathrm{R} \$$ & $2.324 .197,10$ & $61 \%$ \\
2017 & $\mathrm{R} \$$ & $4.319 .299,40$ & $\mathrm{R} \$$ & $2.747 .972,60$ & $63 \%$ \\
\hline
\end{tabular}




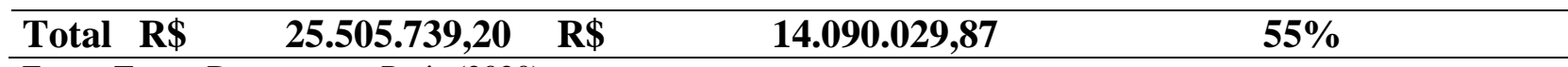

Fonte: Tasca, Deggerone e Paris (2020).

Ressalta-se também que o total de repasses financeiros do Fundo Nacional de Desenvolvimento da Educação (FNDE) foi de $\mathrm{R} \$ 25.505 .739,20$ para a compra de gêneros destinados à alimentação escolar. Apesar de essa informação revelar que os agricultores familiares conseguiram fornecer $55 \%$ dos alimentos destinados aos alimentos dos estudantes, as organizações da agricultura familiar ainda poderiam ter fornecido mais de $\mathrm{R} \$ 11.415 .709,33$ em produtos agroalimentares oriundos dos produtores locais.

Como se pode perceber pelos dados apresentados da operacionalização do PAA e do PNAE na região, muitos agricultores familiares se integraram aos mercados institucionais. Os produtos agroalimentares comercializados foram organizados e operacionalizados por pequenas cooperativas, que foram constituídas para poder viabilizar a participação da agricultura familiar nesses canais de comercialização.

Dentre as cooperativas que passaram a operacionalizar os programas institucionais na região Alto Uruguai, figuram a Cooperativa de Desenvolvimento Regional Ltda (COPERFAMILIA) de Erechim-RS, a Cooperativa da Agricultura Familiar Marcelino Ramos Ltda (COCEL) de Marcelino Ramos-RS, a Cooperativa Microrregional dos Agricultores Familiares (COPEAVE) de São Valentim-RS, e a Cooperativa de Beneficiamento de Derivados de Leite de Mariano Moro (COOPERBEM) de Mariano Moro-RS.

Essas cooperativas possibilitaram, além da comercialização dos produtos da agricultura familiar aos mercados institucionais, a ocupação de outros espaços de comercialização. Dentre esses, foi possibilitada uma maior participação em circuitos curtos de comercialização (feiras de produtores, feiras permanentes, entregas a domicílio, tendas rurais, vendas nas propriedades rurais, colhe e pague, rotas de turismo rural, entre outros espaços). Além disso, essas cooperativas passaram a atuar na organização da produção, o que possibilitou assegurar a melhoria da oferta dos produtos e acessar mais canais de comercialização, dentre os quais os convencionais. Dessa forma, os produtos agroalimentares passaram a ser comercializados em supermercados, redes de distribuição de alimentos e em indústrias processadoras. Também, possibilitaram a criação de espaços permanentes vinculados às cooperativas para a comercialização da produção excedente dos agricultores associados.

Ao participarem desses distintos espaços de venda, os agricultores familiares disponibilizavam aos consumidores diferentes produtos agroalimentares. Dentre os principais, 
podem ser apontados os produtos da horticultura, leite, feijão, mel e produtos agroindustrializados nas propriedades rurais. Entre os principais produtos in natura comercializados, estão alface, cenoura, beterraba, repolho, tomate, cebola..., além das frutas (laranja, bergamota, caqui, pêssego, uva...) e dos alimentos processados (produtos lácteos, carnes e embutidos, mel, sucos, farinhas, panificados, massas, doce de frutas e vegetais minimamente processados).

A venda desses alimentos possibilitou que uma grande parcela de agricultores se mantivesse no meio rural, acessando novos mercados, e superasse os recorrentes problemas produtivos, tecnológicos e econômicos com os quais categoria social convivia. Além disso, essas atividades promoveram a diversificação das atividades produtivas agropecuárias e econômicas nas propriedades rurais e buscaram utilizar estratégias de caráter coletivo para a comercialização dos bens e mercadorias.

No tocante à comercialização da produção de leite, grãos, aves e suínos, a próxima subseção apresenta informações que permitem caracterizar esse período e olhar para o modo como a especialização e a seletividade mercantil aconteceram nessa região.

\section{Especialização e seletividade mercantil na agricultura familiar}

No final dos anos de 1980 e início dos anos de 1990, a produção integrada de aves e suínos representava as formas mais consistentes do processo de externalização da produção agroalimentar. No entanto, nos anos 2000, essas atividades, juntamente com a produção de grãos e a atividade leiteira, passam a liderar o processo de mercantilização, por intermédio da especialização produtiva, que acaba selecionando os produtores que possuem condições econômicas, sociais e ambientais de aderir as inovações sugeridas às atividades produtivas.

No Alto Uruguai, esse processo foi implantado pelas cooperativas Cotrel e Cotrigo, porém, com o fim das operações dessas duas cooperativas, a Cooperalfa ${ }^{\text {xiv }}$ e a Aurora Alimentos ${ }^{\mathrm{xv}}$ passaram a atuar e a se inserir nessas cadeias produtivas. Assim, com o fim das operações da Cotrel e da Cotrigo, várias agroindústrias e comerciantes ${ }^{\mathrm{xvi}}$ passaram a atuar na região $^{\mathrm{xvii}}$. De um modo geral, essas empresas e cooperativas de grande porte passaram a conduzir o processo de inovação nos ramos de produção de aves, suínos, leite e grãos, com a pretensão de ampliar a produção e atender aos padrões institucionais implementados pelo Estado e pelo comércio internacional.

Em termos quantitativos, a produção de grãos (milho, soja, trigo) ao longo dos últimos anos não só ampliou a produtividade como também, em alguns casos, teve a produção duplicada. 
A Figura 4 apresenta o crescimento da produção de milho, soja e trigo na região Alto Uruguai, entre 1974 e 2018.

Os dados revelam que, entre as décadas de 1970 e 1990, a produção agroalimentar mostrou-se estável, em um contexto em que apenas a produção de milho teve crescimento, enquanto a produção de soja e trigo registrou um decréscimo. Porém, a partir dos anos 2000, a produção de soja cresce $192 \%$ em relação à década de 1990, a produção de milho aumenta 45\%, e a produção de trigo cresce $268 \%$ em relação à década passada.

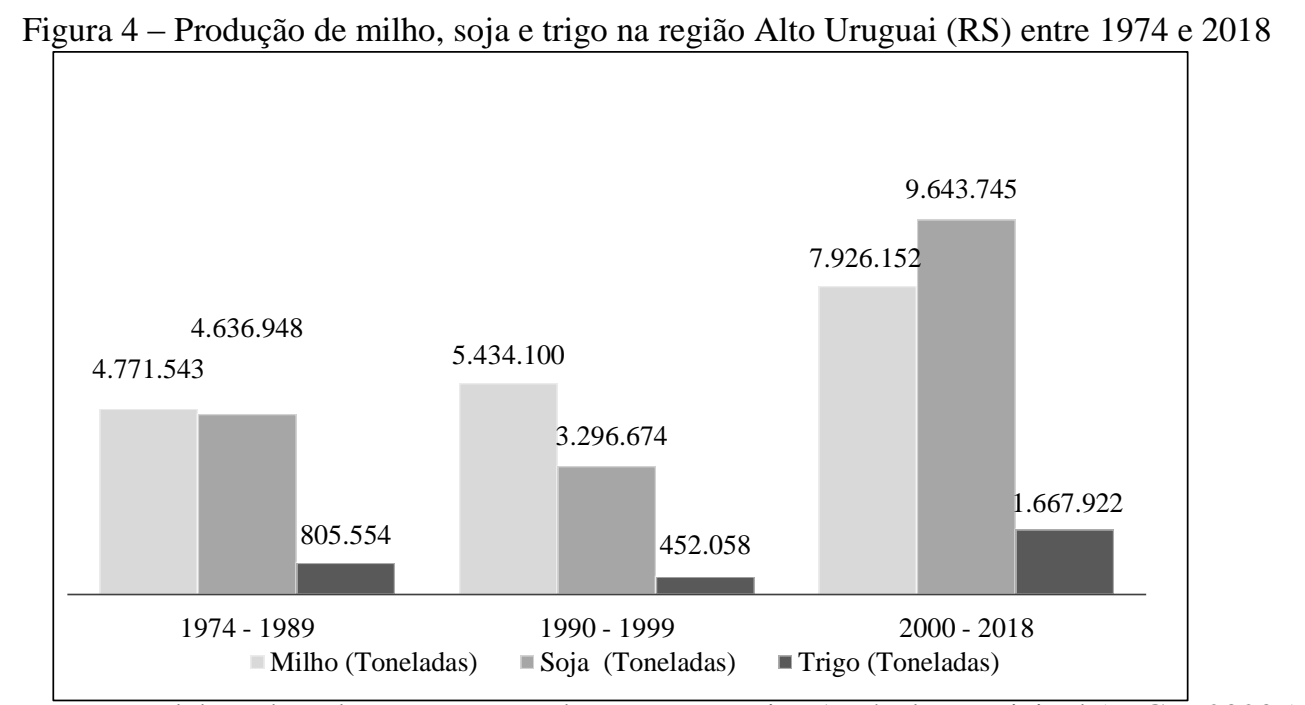

Fonte: Elaborado pelos autores com base em Pesquisa Agrícola Municipal (IBGE, 2020a)

A produção de aves, suínos e de leite na região Alto Uruguai (Figura 5) também apresentou um crescimento ao longo dos períodos analisados. A produção de aves cresceu $174 \%$ em relação aos anos 1990, a produção de suínos aumentou 171\%, e a produção de leite aumentou $336 \%$ quando comparada à década passada.

Figura 5 - Produção de aves, suínos e de leite na região Alto Uruguai (RS) entre 1974 a 2018. 


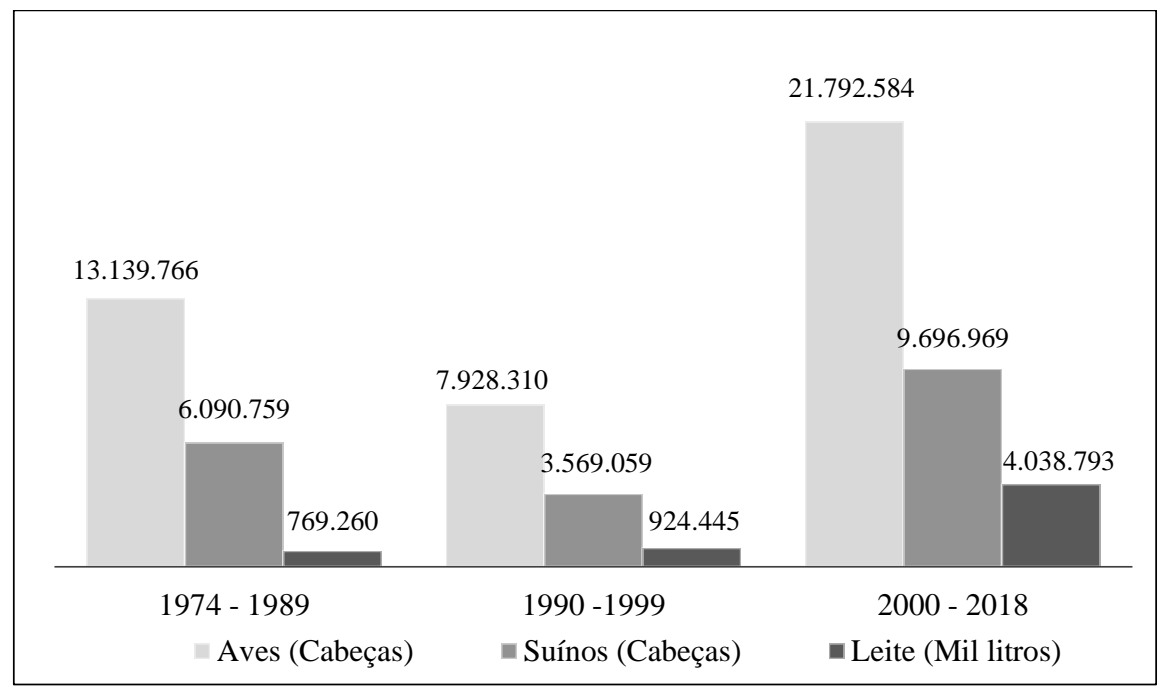

Fonte: Elaborado pelos autores com base em Pesquisa Agrícola Municipal (IBGE, 2020b,c).

Como pode ser observado em relação a esses ramos de produção, todos apresentaram um crescimento expressivo na região. Entre as hipóteses que explicam esse aumento, estão as melhorias nas condições estruturais das unidades de produção familiares, proporcionadas pelo acesso aos recursos do Pronaf (Figuras 2 e 3), aliadas às inovações em tecnologias mecânicas, biológicas e químicas que garantiram o aumento da produção agroalimentar.

Esse crescimento vertiginoso na produção agroalimentar, no entanto, está atrelado ao incessante processo de mercantilização da produção primária, associado à especialização da produção agroalimentar. A especialização tem relação direta com a adoção de processos produtivos uniformes, a divisão do trabalho, a intensificação do processo produtivo e a busca de maior eficiência em termos de redução de custos e de mão de obra para aumentar a margem de rentabilidade das atividades produtivas.

No campo teórico, os autores Davis e Goldberg (1957) foram pioneiros na observação do que eles chamaram de "dispersão de funções" da agricultura, quando o processo de modernização traria uma consistente divisão de tarefas conduzida pela necessidade de maior eficiência econômica. Isso poderia ser obtido pela "especialização" das atividades de produção, incorporando nesse setor a dinâmica trazida pela maior divisão do trabalho que se observava nos demais setores da economia.

Esse processo - que aconteceu mais tardiamente no meio rural - trouxe algumas implicações para os agricultores familiares. A próxima seção deste ensaio procura evidenciar que esses atores sociais, mesmo se tornando produtores simples de mercadorias, não perderam as 
características que os distinguem das outras categorias sociais por conta da crescente presença nos espaços de troca.

\section{IMPLICAÇÕES DO PROCESSO DE MERCANTILIZAÇÃO PARA OS AGRICULTORES FAMILIARES}

As implicações do processo de mercantilização para a agricultura familiar dessa região estão associadas à transformação dos colonos ou agricultores familiares em produtores simples produtores de mercadorias. A reprodução social e econômica dessa categoria social está relacionada a um determinado modelo de produção, que, por sua vez, associa-se à produção de commodities e de outras atividades produtivas direcionadas ao autoprovisionamento e à complementação da renda do grupo familiar. Desse modo, é muito comum, nessa região, as propriedades rurais desenvolverem a bovinocultura leiteira conectada à produção de grãos; ou se dedicarem à suinocultura integrada à produção de frutas (laranja); ou mesmo realizarem a atividade avícola associada à atividade bovinocultura de corte, entre outras atividades produtivas inerentes ao meio rural.

Esses agricultores familiares criaram um sistema híbrido de produção e comercialização de produtos agroalimentares no qual diferentes atividades produtivas coexistem em uma única propriedade rural, mas não necessariamente são homogêneas entre agricultores familiares de uma determinada comunidade rural, município ou região. Isso ocorre em razão de que cada agricultor implementa um repertório produtivo que atende às condições de reprodução social do grupo familiar, mas também leva em consideração a infraestrutura existente nas unidades de produção, o conhecimento prévio das atividades produtivas, a disponibilidade de mão de obra para atuar na atividade produtiva e as políticas públicas disponíveis, além de outros fatores institucionais/culturais que acabam influenciando a decisão desses atores sociais.

Essa característica existente na região Alto Uruguai decorre de um conjunto de disputas e complementariedades que geraram um processo de adaptação dos agricultores familiares à dinâmica mercadológica. Essa trajetória foi influenciada pela atuação do Estado na criação de mecanismos institucionais (leis, portarias, decretos), além de políticas públicas de comercialização, a exemplo do PAA e do PNAE, para a inserção dos agricultores familiares. Nesse sentido, importante salientar que a política pública de crédito ofereceu condições para que ocorressem a modernização das atividades produtivas e o crescimento da produção agroalimentar, 
o que resultou na ampliação do processo de mercantilização, seja na criação de circuitos curtos de venda ou aderindo aos circuitos longos de comercialização.

As organizações coletivas (cooperativas), comerciantes e agroindústrias também contribuíram com o processo de integração mercantil. Essas organizações, através das atividades de assessoramento, incentivaram os agricultores familiares a adotarem padrões produtivos cada vez mais dependentes de insumos, aumentando, assim, a relação mercantil condicionada à produção e, posteriormente, à comercialização dos produtos agroalimentares.

Essa relação, segundo Conterato (2004), pode ser tomada como um processo no qual a produção familiar passa ter a sua reprodução cada vez mais dependente das suas relações com os espaços de venda, passando a vincular-se com o mercado num processo gradual e contínuo. Porém, Perondi (2007) enfatiza que esse vínculo serve para adequar o estoque de insumos e o fluxo de alimentos e de recursos financeiros que sejam suficientes para garantir as necessidades básicas e as novas estratégias de reprodução social.

Nesse caso, a inserção dos agricultores familiares do Alto Uruguai-RS em circuitos mercantis, enquanto produtores simples de mercadorias, não implica, necessariamente, que se esteja produzindo uma agricultura capitalista, regida pela subordinação do trabalho em relação ao capital. Isso porque uma agricultura mais mercantil não significa uma agricultura menos familiar, pois as normas, as regras e os valores sociais que regem as relações entre os indivíduos no interior do grupo familiar não desaparecem em razão da intensificação das trocas. Isso se confirma em razão de que se mantém a autonomia relativa sobre os fatores e os meios de produção particularmente a terra e a força de trabalho, como evidenciado por Friedmann (1978) -, porque a agricultura familiar consegue se vincular aos mais diversos mercados sem destituir o seu caráter familiar.

E ainda é preciso enfatizar que as transformações sociais e históricas que aconteceram nessa região estão presentes nas características coletivas desses atores sociais. Por isso, é importante ressaltar que a mercantilização dos agricultores familiares condicionou-os a adaptaremse às exigências mercadológicas, a transformarem as formas de produção e a diferenciarem seus produtos e processos. Essa capacidade de adaptação dos agricultores a diferentes processos produtivos está associada justamente à centralidade do grupo familiar e das instituições sociais na capacidade de estruturar as relações econômicas e de reconstruir as estratégias sociais e produtivas voltadas ao fortalecimento dessa categoria social no meio rural. 


\section{CONSIDERAÇÕES FINAIS}

A elaboração deste artigo permitiu evidenciar alguns elementos sócio-históricos que exerceram influência no processo de mercantilização dos agricultores familiares na Região Alto Uruguai-RS. Dentre os aspectos analisados, constatou-se de que a mercantilização dos agricultores familiares é decorrente das interações sociais e de relações de poder que aconteceram ao longo de pelo menos cinco períodos históricos.

A primeira fase desses períodos históricos caracteriza-se pela ocupação do território do Alto Uruguai e pela inserção mercantil dos agricultores familiares no período de 1900 a 1939 . O segundo período ficou marcado pela diversificação produtiva agroalimentar, que desencadeou a expansão do comércio e o surgimento do capital agroindustrial entre 1940 e 1969. A terceira fase deu continuidade ao processo de mercantilização da agricultura familiar e à consolidação dos complexos agroindustriais no período compreendido entre 1970 e 1989. O quarto período compreendeu o início dos anos 1990 até o final dos anos 2000, quando ocorre a manutenção dos processos de mercantilização associados à intensificação da produção de grãos e à seleção dos produtores integrados ao complexo de carnes.

A partir dos anos 2000, verificou-se a continuidade do processo de mercantilização e da especialização produtiva dos agricultores familiares. Esse período foi influenciado pela atuação do Estado na criação de mecanismos institucionais (leis, portarias, decretos), além de políticas públicas de comercialização, a exemplo do PAA e do PNAE, para a inserção dos agricultores familiares em espaços de venda. Verificou-se também que as políticas públicas de crédito e investimento ofereceram condições para que ocorresse a modernização das atividades produtivas e o crescimento da produção agroalimentar, o que resultou na ampliação do processo de mercantilização dos agricultores familiares.

As implicações desse processo de mercantilização estão associadas à transformação dos agricultores familiares em produtores simples de mercadorias. A reprodução social e econômica dessa categoria social está relacionada a um determinado modelo de produção, que, por sua vez, associa-se à produção de commodities e de outras atividades produtivas direcionadas ao autoprovisionamento e à complementação da renda do grupo familiar.

Porém, é preciso enfatizar que uma agricultura mais mercantil não significa uma agricultura menos familiar, pois as normas, as regras e os valores sociais que regem as relações entre os indivíduos no interior do grupo familiar não desaparecem em razão da intensificação das trocas. Isso se confirma em razão de que se mantém a autonomia relativa sobre os fatores e os 
meios de produção, porque a agricultura familiar consegue se vincular aos mercados de proximidade, territoriais, convencionas e institucionais sem destituir o seu caráter familiar.

\section{REFERÊNCIAS}

ABRAMOVAY, R. Paradigmas do capitalismo agrário em questão. São Paulo: Hucitec, 1992.

ABRAMOVAY, R. et al. Mercados do empreendedorismo de pequeno porte no Brasil. In: Comissão Econômica para a América Latina e Caribe (CEPAL). DEPARTAMENT FOR INTERNATIONAL DEVELOPMENT (DFID). Pobreza e mercados no Brasil: Uma análise de inciativas de políticas públicas. Brasília: CEPAL; DFID, 2003.

ABRAMOVAY, R. O futuro das regiões rurais. Porto Alegre: Editora da UFRGS, 2003.

BARDIN, L. Análise de conteúdo. São Paulo: Edições 70, 2011.

BANCO CENTRAL DO BRASIL (BACEN). Matriz de Dados do Crédito Rural (MDCR):

Quantidade e Valor dos Contratos de Custeio por Município e Produto. Disponível em:https://www.bcb.gov.br/estabilidadefinanceira/reportmicrrural?path=conteudo\%2FMDCR\%2F Reports $\% 2 \mathrm{FqvcCusteioMunicipioProduto.rdl \& nome=Quantidade} \% 20 \mathrm{e} \% 20$ Valor $\% 20 \mathrm{dos} \% 20 \mathrm{Con}$ tratos $\% 20 \mathrm{de} \% 20 \mathrm{Custeio} \% 20$ por $\% 20 \mathrm{Munic} \% \mathrm{C} 3 \% \mathrm{ADpio} \% 20 \mathrm{e} \% 20$ Produto\&exibeparametros=tru e\&botoesExportar=trueAcesso. Acesso em: 11 Out. 2020a.

BANCO CENTRAL DO BRASIL (BACEN). Matriz de Dados do Crédito Rural (MDCR): Quantidade e Valor dos Contratos de Investimento por Município e Produto. Disponível em: https://www.bcb.gov.br/estabilidadefinanceira/reportmicrrural?path=conteudo\%2FMDCR\%2FRep orts $\% 2$ FqveInvestimentoMunicipioProduto.rdl\&nome=Quantidade $\% 20 \mathrm{e} \% 20$ Valor $\% 20 \mathrm{dos} \% 20 \mathrm{Co}$ ntratos\%20de\%20Investimento\%20por\%20Munic\%C3\%ADpio\%20e\%20Produto\&exibeparametr os $=$ true \&botoesExportar=true. Acesso em: 11 Out. $2020 \mathrm{~b}$.

CASSOL, A. P. Redes agroalimentares alternativas: mercados, interação social e a construção da confiança. 2013. Dissertação (Mestrado em Sociologia) - Faculdade de Ciências Econômicas, Universidade Federal do Rio Grande do Sul, Porto Alegre, 2013.

CASSOL, A. P. Instituições sociais e mercados alimentares tradicionais: barganha, preços, variedade, qualidade e consumo em feiras. 2018. Tese (Doutorado em Sociologia) - Faculdade de Ciências Econômicas, Universidade Federal do Rio Grande do Sul, Porto Alegre, 2018.

CONTERATO, M. A. A mercantilização da agricultura familiar no Alto Uruguai/RS: um estudo de caso no município de Três Palmeiras. 2009. Dissertação (Mestrado em Desenvolvimento Rural) - Faculdade de Ciências Econômicas, Universidade Federal do Rio Grande do Sul, Porto Alegre, 2004.

CHIAPARINI, E. J. et al. Erechim: Retratos do passado - Memórias no Presente. Erechim: Graffoluz, 2012. 
DAVIS, J. H.; GOLDBERG, R. A. A Concept of Agribusiness. Boston: Harvard University Graduate School of Business Administration, 1957.

FERRARI, D. L. Cadeias agroalimentares curtas: a construção social de mercados de qualidade pelos agricultores familiares em Santa Catarina. 2011. Tese (Doutorado em Desenvolvimento Rural) - Faculdade de Ciências Econômicas, Universidade Federal do Rio Grande do Sul, Porto Alegre, 2011.

GAZOLLA, M. Cadeias curtas agroalimentares na agroindústria familiar: dinâmicas e atores envolvidos. In: GAZOLLA, M; SCHNEIDER, S. (Org.). Cadeias curtas e redes agroalimentares alternativas. Porto Alegre: Editora da UFRGS, 2017, p. 175-194.

GAZOLLA, M.; SCHNEIDER, S. Qual "fortalecimento" da agricultura familiar?: uma análise do Pronaf crédito de custeio e investimento no Rio Grande do Sul. Rev. Econ. Sociol. Rural, Brasília, v. 51, n.1, p. 45-68, 2013. Disponível em:

http://www.scielo.br/scielo.php?script=sci_arttext\&pid=S010320032013000100003\&lng=en\&nrm =iso. Acesso em 10 jul. 2021.

GRISA, C. Desenvolvimento local, políticas públicas e meios de vida: uma análise do Programa de Aquisição de Alimentos (PAA). In: Congresso da Sociedade Brasileira de Economia, Administração e Sociologia Rural, 47, 2009, Porto Alegre (RS), Anais...Porto Alegre (RS): SOBER, 2009.

GRISA, C. As redes e as instituições do Programa de Aquisição de Alimentos (PAA). Revista Brasileira de Gestão e Desenvolvimento Regional, Taubaté, v. 6, p. 97-129, 2010. Disponível em: https://www.rbgdr.net/revista/index.php/rbgdr/article/ view/274/193. Acesso em: 30 jan. 2021.

GRISA, C. Políticas públicas para a Agricultura Familiar no Brasil: produção e institucionalização das ideias. 2012. Tese (Doutorado em Ciências) - Instituto de Ciências Humanas e Sociais, Universidade Federal Rural do Rio de Janeiro. Rio de Janeiro, 2012.

GRISA, C. et al. Contribuições do Programa de Aquisição de Alimentos à segurança alimentar e nutricional e à criação de mercados para a agricultura familiar. Agriculturas, v. 8, n. 3, p. 34-41, 2011.

GRISA, C.; WESZ JUNIOR, V. Políticas públicas para a agricultura familiar: entre avanços e desafios. Boletim do OPPA, n. 3, 2010.

GRISA, C.; JUNIOR, V. J. W.; BUCHWEITZ, V. D. Revisitando o Pronaf: velhos questionamentos, novas interpretações. Revista de Economia e Sociologia Rural, Brasília, 52, n. 2, 2014. Disponível em:

https://www.scielo.br/scielo.php?script=sci_arttext\&pid=S010320032014000200007\&lang=en. Acesso em: 10 jul. 2021.

GRISA, C.; SCHNEIDER, S. Três gerações de políticas públicas para a agricultura familiar e formas de interação entre sociedade e estado no Brasil. Revista de Economia e Sociologia Rural, Brasília, v. 52, supl. 1, p. 125-146, 2014. Disponível em: 
http://www.scielo.br/scielo.php?script=sci_arttext\&pid=S010320032014000600007\&lng=en\&nrm =iso. Acesso em: 10 jul. 2021.

INSTITUTO BRASILEIRO DE GEOGRAFIA E ESTÁTISTICA (IBGE). Pesquisa Agrícola Municipal. Tabela 1612 - Área plantada, área colhida, quantidade produzida, rendimento médio e valor da produção das lavouras temporárias. 2020a. Disponível em:

https://sidra.ibge.gov.br/Tabela/3939. Acesso em: 26 Jan. 2020

INSTITUTO BRASILEIRO DE GEOGRAFIA E ESTÁTISTICA (IBGE). Pesquisa da Pecuária Municipal. Tabela 74 - Produção de origem animal, por tipo de produto. 2020b. Disponível em: https://sidra.ibge.gov.br/tabela/74. Acesso em: 26 Jan. 2020

INSTITUTO BRASILEIRO DE GEOGRAFIA E ESTÁTISTICA (IBGE). Pesquisa da Pecuária Municipal. Tabela 3939 - Efetivo dos rebanhos, por tipo de rebanho. 2020c. Disponível em: https://sidra.ibge.gov.br/Tabela/3939. Acesso em: 26 Jan. 2020

NIEDERLE, P. A.; WESZ JUNIOR, V. J. As novas ordens alimentares. Porto Alegre: Editora da UFRGS, 2018. 429p.

MALUF, R. S. Segurança alimentar e desenvolvimento econômico na América Latina: o caso do Brasil. Revista de Economia Política, São Paulo, v. 15, n. 1(57), p. 134-140, 1995.

MALUF, R. S. Mercados agroalimentares e a agricultura familiar no Brasil: agregação de valor, cadeias integradas e circuitos regionais. Ensaios FEE, Porto Alegre, v. 25, n. 1, p. 299-322, 2004.

MATTEI, L. Evolução do crédito do PRONAF para as categorias de agricultores A e A/C entre 2000 e 2010. In: Congresso da Sociedade Brasileira de Economia, Administração e Sociologia Rural, 49, 2011, Belo Horizonte (MG), Anais...Belo Horizonte (MG): SOBER, 2011.

OLIVEIRA, D. Produção de novidades no desenvolvimento rural: o caso da associação dos agricultores ecologistas de Ipê e Antônio Prado/RS. 2014. Tese (Doutorado em Desenvolvimento Rural) - Faculdade de Ciências Econômicas, Universidade Federal do Rio Grande do Sul, Porto Alegre, 2014.

PERONDI, M. A. Diversificação dos meios de vida e mercantilização da agricultura familiar. Porto Alegre. 2007. Tese (Doutorado em Desenvolvimento Rural) - Faculdade de Ciências Econômicas, Universidade Federal do Rio Grande do Sul, Porto Alegre. 2007.

PIRAN, N. Agricultura familiar: lutas perspectivas no Alto Uruguai. Erechim: EDIFAPES, 2001.

POLANYI, K. A Grande Transformação: as origens da nossa época. Rio de Janeiro: Elsevier, 2012.

PLEIN, C. As metamorfoses da agricultura familiar: o caso do município de Iporã d'Oeste, Santa Catarina. 2003. Dissertação (Mestrado em Desenvolvimento Rural) - Faculdade de Ciências Econômicas, Universidade Federal do Rio Grande do Sul, Porto Alegre, 2003.

PLOEG, J. D. V. El processo de trabajo agrícola y lamercantilización. In: GUZMÁN, E. S. e MOLINA, M. G. (Org.). Ecologia, campesinato e história. Madrid: La Piqueta, 1992, p. 153-195. 
PLOEG, J. D. V. O modo de produção camponês revisitado. In: SCHNEIDER, S. (Org). A diversidade da agricultura familiar. Porto Alegre: Editora da UFRGS, 2006. p. 15-58.

PLOEG, J. D. V. ; JINGZHONG, Y.; SCHNEIDER, S. Rural development through Ploeg the construction of new, nested markets: comparative perspectives from China, Brazil and the European Union. Journal of Peasant Studies, London, v. 39, n. 1, p. 133-173, 2012.

PLOEG, J. D. V. Camponeses e a arte da agricultura: um manifesto chayanoviano. Estudos camponeses e mudança agrária. São Paulo; Porto Alegre: Editora UNESP; Editora UFRGS, 2016.

REAL, L. C. V.; SCHNEIDER, S. O uso de programas públicos de alimentação na reaproximação do pequeno produtor com o consumidor: o caso do programa de alimentação escolar. Artigo \& Debate, Lajeado v. 18, n. 2, p. 57-79, 2011.

SALVATE BRASIL, N. Mercados Imersos: uma nova abordagem sobre a construção social de mercados. 2019. Tese (Doutorado em Desenvolvimento Rural) - Faculdade de Ciências Econômicas, Universidade Federal do Rio Grande do Sul, Porto Alegre, 2019.

SECRETARIA DE AGRICULTURA, PECUÁRIA E DESENVOLVIMENTO RURAL SAPDR/RS. Programa de Aquisição de Alimentos (PAA) no Corede Norte. 2020

SEMINOTTI, J. J. Os agricultores familiares e a representação política do Sutraf na Região Alto Uruguai do RS. Passo Fundo: Editora da UPF, 2014. Disponível em: http://editora.upf.br/images/ebook/a_dinamica_sociopolitica.pdf. Acesso em: 10 nov. 2020.

SCARBELOT, M. Construção de cadeias agroalimentares curtas em Nova Veneza, SC. 2012. Dissertação (Mestrado em Desenvolvimento Rural) - Faculdade de Ciências Econômicas, Universidade Federal do Rio Grande do Sul, Porto Alegre, 2012.

SCHNEIDER, S. Pluriatividade na Agricultura Familiar. Porto Alegre: Editora da UFRGS. 2003.

SCHNEIDER, S. Mercados e agricultura familiar. In: MARQUES, F. C.; CONTERATO, M. A.; SCHNEIDER, S. (Org.). Construção de mercados e agricultura familiar: desafios para o desenvolvimento rural. Porto Alegre: Editora da UFRGS, 2016. p. 93-135.

SCHNEIDER, S.; SALVATE, N.; CASSOL, A. Nested Markets, Food Networks, and New Pathways for Rural Development in Brazil. Agriculture, v. 6, n. 4, p. 1-19, nov. 2016.

SCHNEIDER, S. A presença e as potencialidades da Agricultura Familiar na América Latina e no Caribe. Redes (St. Cruz do Sul Online), Santa Cruz do Sul, v. 21, n. 3, p. 11-33, 2016. Disponível em: https://online.unisc.br/seer/index.php/redes/article/view/8390. Acesso em: 14 set. 2021. DOI: https://doi.org/10.17058/redes.v21i3.8390.

SERPA, I. M. Da produção colonial ao sistema agroindustrial: a modificação do perfil produtivo da região de Chapecó (1920-1980). 2014. Dissertação (Mestrado em História) - Instituto de Filosofia e Ciências Humanas, Universidade de Passo Fundo, Passo Fundo, 2014. 
SILVA, G. P. A construção social dos circuitos curtos de comercialização e consumo de alimentos: a emergência de novas institucionalidades. 2016. Tese (Doutorado em Extensão Rural) - Universidade Federal de Santa Maria, Santa Maria, 2016.

TASCA, E; DEGGERONE, Z.A; PARIS, C. A. O fortalecimento da agricultura familiar no território Alto Uruguai (RS): implementação do Programa Nacional de Alimentação Escolar (PNAE). Grifos, Chapecó, v. 29, n. 50, p. 103-125, 2020. Disponível em: https://bell.unochapeco.edu.br/revistas/index.php/grifos/article-/view/5238. Acesso em 6 jun. 2020. DOI: https://doi.org/10.22295/grifos.v29i50.5238

TRICHES, R. M. Reconectando a produção ao consumo: a aquisição de gêneros alimentícios da agricultura familiar para o programa de alimentação escolar. 2012. Tese (Doutorado em Desenvolvimento Rural) - Faculdade de Ciências Econômicas, Universidade Federal do Rio Grande do Sul, Porto Alegre, 2012.

TRICHES, R. M. Repensando o mercado da alimentação escolar: novas institucionalidades para o desenvolvimento rural. In: GRISA, C.; SCHNEIDER, S. (Org.). Políticas públicas de desenvolvimento rural no Brasil. Porto Alegre: Editora da UFRGS, 2015. p. 181-200.

WESZ JUNIOR, V. J. O Pronaf pós-2014: intensificando a sua seletividade? Grifos, Chapecó, v. 30, n. 51, p. 89-113, 2020. Disponível em:

https://bell.unochapeco.edu.br/revistas/index.php/grifos/article/view/5353. Acesso em 7 jun. 2021. DOI: https://doi.org/10.22295/grifos.v30i51.5353

WILKINSON, J. Mercados, redes e valores: o novo mundo da agricultura familiar. Porto Alegre: Editora da UFRGS, 2008.

\section{ZANELLA, A. A Trajetória do Sindicalismo no Alto-Uruguai Gaúcho (1937-2003). Passo} Fundo: UPF, 2004.

\footnotetext{
${ }^{i}$ Segundo Schneider (2016), a agricultura familiar é uma forma particular de organização de trabalho e de produção que existe e se reproduz a partir de distintas estratégias produtivas agrícolas e não agrícolas em consonância com o contexto social e econômico em que estão inseridos. Sua reprodução social está condicionada por fatores internos que estão relacionados ao modo concreto como as famílias gerenciam seus recursos produtivos (terra, capital, tecnologia, etc...), tomam decisões de investimento e dispêndio, alocam o trabalho de seus membros e aderem aos valores culturais do grupo a que pertencem.

ii A produção simples de mercadorias (PSM) pressupõe, com exceção do trabalho, que todos os demais recursos materiais e sociais entram no processo de trabalho como mercadorias. Nesse sentido, Ploeg (2016) argumenta que a maneira de produzir e suas relações de produção estão ancoradas na lógica de mercado. Ou seja, o produtor vende as mercadorias produzidas com o seu trabalho e consegue o dinheiro para repor o estritamente necessário para renovar o processo produtivo, do que consta inclusive reproduzir a força de trabalho, no caso, comprar os meios de vida indispensáveis à sua família.

iii Os municípios que fazem parte da região são: Aratiba, Áurea, Barão de Cotegipe, Barra do Rio Azul, Benjamin Constant do Sul, Campinas do Sul, Carlos Gomes, Centenário, Charrua, Cruzaltense, Entre Rios do Sul, Erebango, Erechim, Erval Grande, Estação, Faxinalzinho, Floriano Peixoto, Gaurama, Getúlio Vargas, Ipiranga do Sul, Itatiba do Sul, Jacutinga, Marcelino Ramos, Mariano Moro, Paulo Bento, Ponte Preta, Quatro Irmãos, São Valentim, Sertão, Severiano de Almeida, Três Arroios e Viadutos. Além disso, parte desses municípios fazem divisa com o Rio Uruguai e com o estado de Santa Catarina.
} 
iv Piran, nos anos 2000, identificou quatro fases de desenvolvimento da agricultura familiar nessa região (PIRAN, 2001).

v A atividade suinícola possibilitava o fornecimento de carne para a família e propiciava o aproveitamento da banha, que era utilizada tanto na alimentação e na conservação dos alimentos quanto como combustível para os lampiões que iluminavam as residências.

vi A expressão "Revolução verde" esteve associada ao propósito de aumentar a produção agrícola através do desenvolvimento de pesquisas em sementes, uso de agrotóxicos, fertilização do solo e utilização de máquinas no campo que aumentassem a produtividade. Isso se daria por meio do desenvolvimento de sementes adequadas para tipos específicos de solos e climas, adaptação do solo para o plantio e desenvolvimento de máquinas.

vii Essa dinâmica mercadológica é conhecida por sistema de integração ou "parceria". Serpa (2014) argumenta que esse sistema visava dar suporte aos produtores de suínos ${ }^{\text {vii }}$, por meio do fornecimento de insumos, assistência técnica e alimentação, e ressalta que os agricultores ficavam responsáveis pelas instalações e se comprometiam em comercializar a produção somente para as cooperativas.

viii O quadro macroeconômico nacional dos anos 1990 foi marcado, segundo Grisa e Schneider (2014), pela liberalização comercial e pelo desmonte do modelo de intervenção do Estado; pela criação do Mercosul, em 1991, o que afetou negativamente os setores lácteos, tritícola, vitivinícola e de frutas no sul do Brasil; pela adoção do plano real, em 1994, que provocou a queda da renda real do setor agrícola de 20\% a 30\% no primeiro semestre de 1995; pela valorização da taxa de câmbio, associada ao grande volume de recursos disponíveis no sistema financeiro internacional; e as elevadas taxas de juros domésticas beneficiaram o aumento das importações de produtos agrícolas e o decréscimo das exportações. Além disso, nesse período, sucessivas estiagens ocasionaram a frustração de várias safras agrícolas, e as medidas mencionadas prejudicaram a reprodução social e econômica da agricultura familiar, afetada pelas consequências da modernização da agricultura.

${ }^{\text {ix }}$ Dentre as principais regulamentações e legislações, podem ser citadas: - o regime de comércio internacional da Organização Mundial do Comércio (OMC); as regras no âmbito da Organização Mundial da Saúde Animal (OIE), da Organização Mundial da Saúde (OMS); da Comissão do Codex Alimentarius da Organização das Nações Unidas para a Agricultura e a Alimentação (FAO) em conjunto com a OMS.

${ }^{x}$ Dentre as principais linhas operadas pelo Pronaf, destacam-se: Pronaf Custeio, Pronaf Agroindústria, Pronaf Mais Alimentos, Pronaf Grupo B, Pronaf Mulher, Pronaf Agroecologia, Pronaf ECO, Pronaf Jovem, Pronaf Microcrédito (Grupo "B").

${ }^{x i}$ O Programa de Aquisição de Alimentos (PAA) foi instituído pelo art. 19 da Lei n 10.696 , de 02 de julho de 2003 , no âmbito do Programa Fome Zero. Essa lei foi alterada pela Lei $\mathrm{n}^{\mathrm{o}} 12.512$, de 14 de outubro de 2011, e regulamentada por diversos decretos, sendo que o que está em vigência é o Decreto nº 7.775 , de 4 de julho de 2012 .

xii As modalidades executadas do PAA são: Doação Simultânea, Compra Direta, Formação de Estoques, PAA Leite e Compra Institucional.

xiii Salienta-se que não foi possível sintetizar todos os valores financeiros relativos às compras realizadas pelo PAA na região do Alto Uruguai desde a sua institucionalização até o presente momento.

${ }^{\text {xiv }}$ Passou a atuar no fomento à produção, na loja agropecuária e na comercialização de grãos.

${ }^{x v}$ Esta cooperativa adquiriu os frigoríficos de aves, suínos, fábrica de rações e todo o sistema de fomento à produção de aves e suínos da Cotrel. A Cooperativa de Produção e Consumo Concórdia (COPÉRDIA), de Concórdia - SC, que já atuava na região, no fomento à produção de suínos, permaneceu na sua área de abrangência.

${ }^{\text {xvi }} \mathrm{Na}$ área de atuação da Cotrigo, a Cooperativa Santa Clara de Carlos Barbosa (RS) passou a atuar na cadeia do leite, e o Grupo Olfar de Erechim passou a atuar na cadeia de grãos. 
xvii Dentre as principais comerciantes na área de grãos que depois passaram a agroindustrializar os produtos, podem ser citados: o Grupo Olfar e a Vaccaro e a Oleoplan. O grupo das Sementes Estrela permaneceu na atividade de produção e comercialização de grãos. 